\title{
Five-year extension of a clinical trial comparing the EX-PRESS glaucoma filtration device and trabeculectomy in primary open-angle glaucoma
}

This article was published in the following Dove Press journal:

Clinical Ophthalmology

22 April 2011

Number of times this article has been viewed

Leo de Jong'

Antoine Lafuma ${ }^{2}$

Anne-Sophie Aguadé

Gilles Berdeaux ${ }^{3,4}$

'Academic Medical Centre, Ophthalmology Department, Amsterdam, The Netherlands, ${ }^{2}$ Cemka-Eval, Bourg la Reine, Paris, France, ${ }^{3}$ Alcon France, Rueil-Malmaison, Paris, France, ${ }^{4}$ Conservatoire National des Arts et Métiers, Paris, France

Correspondence: Gilles Berdeaux Alcon France, 4 rue Henri Sainte Claire Deville, 92500 Rueil-Malmaison, France Tel +33 I4 7I 04860

Fax +33 147102770

Email gilles.berdeaux@alconlabs.com
Background: This study compared the efficacy of the EX-PRESS ${ }^{\circledR}$ glaucoma filtration device and trabeculectomy in primary open-angle glaucoma up to five years after surgery.

Methods: Patients from a previously reported randomized, open-label, parallel-arm clinical trial in which 78 patients received either the EX-PRESS glaucoma filtration device or underwent a trabeculectomy were followed for up to an additional four years (five total) beyond the original study (39 eyes per treatment group). Risk-benefit data were obtained for up to five years after glaucoma surgery. Outcome variables were intraocular pressures and intraocular pressure medications. Complete success was denoted by intraocular pressure values $\leq 18 \mathrm{mmHg}$ without medication.

Results: The EX-PRESS glaucoma filtration device controlled intraocular pressure more effectively without medication for more patients from year $1(86.8 \%$ versus $61.5 \%, P=0.01)$ to year $3(66.7 \%$ versus $41.0 \%, P=0.02)$ than trabeculectomy. At year 1 , only $12.8 \%$ of patients required intraocular pressure medication after EX-PRESS implantation, compared with $35.9 \%$ after trabeculectomy. The proportions became closer at year 5 ( $41 \%$ versus $53.9 \%)$. The responder rate was higher with EX-PRESS and time to failure was longer. In addition, surgical interventions for complications were fewer after EX-PRESS implantation.

Conclusion: This five-year analysis confirmed and extended the results reported after one year Compared with trabeculectomy, EX-PRESS provided better intraocular pressure control in the first three years, and patients required fewer intraocular pressure medications and fewer surgical interventions during the five-year study period. For patients with primary open-angle glaucoma, the EX-PRESS glaucoma filtration device, implanted under a superficial scleral flap, produced significantly higher success rates than trabeculectomy. EX-PRESS is an effective device for long-term treatment of primary open-angle glaucoma.

Keywords: glaucoma filtration device, trabeculectomy, primary open-angle glaucoma, intraocular pressure, medication

\section{Introduction}

Open-angle glaucoma is a progressive optic neuropathy, resulting in loss of retinal ganglion cells leading to progressive damage of the visual field. Glaucoma is a leading cause of blindness in Western developed countries. ${ }^{1-3}$ Glaucoma treatments are directed at reducing intraocular pressure, ${ }^{4,5}$ either pharmacologically or surgically. Surgery is performed when intraocular pressure medication and laser treatment cease to control intraocular pressure. ${ }^{6}$ Trabeculectomy is the usual surgical procedure. ${ }^{7}$

An alternative procedure is to implant the EX-PRESS ${ }^{\circledR}$ glaucoma filtration device (Alcon Inc, Forth Worth, TX). The device is a small stainless steel, nonvalved 
flow-restricting device, designed to lower intraocular pressure in glaucomatous eyes. ${ }^{8}$ It was developed as a less invasive surgical procedure ${ }^{9,10}$ compared with conventional trabeculectomy, because it is inserted under a scleral flap to shunt aqueous humor from the anterior chamber to the subconjunctival space using a filtration bleb. ${ }^{11}$

Several studies have reported on the efficacy of EX-PRESS, ${ }^{9,12-15}$ but only one randomized the surgical procedures. ${ }^{12}$ While the efficacy results consistently demonstrated significant intraocular pressure reductions, they differed in the frequency of complications, with more such events occurring with earlier surgical techniques in which the EX-PRESS device was implanted under a conjunctival flap. ${ }^{9,14,15}$ Since then, the implantation procedure has evolved, and the EX-PRESS device is now implanted under a scleral flap with similar efficacy results, ${ }^{12,13}$ and the postoperative complication rates have improved considerably.

In the only prospective randomized trial published to date, de Jong ${ }^{12}$ randomized patients to either trabeculectomy or EX-PRESS and assessed the results one year after surgery. de Jong found better intraocular pressure control $(P=0.02)$ in patients implanted with EX-PRESS (12.0 mmHg) compared with trabeculectomy $(13.9 \mathrm{mmHg})$, fewer prescriptions for intraocular pressure medications, and higher responder rates with intraocular pressure thresholds fixed at either $15 \mathrm{mmHg}$ or $18 \mathrm{mmHg}$. Also, patients who received EX-PRESS implantation went significantly longer without the need for intraocular pressure medications.

Lifelong treatment of glaucoma is necessary to ensure intraocular pressure control and prevent disease progression. Hence documentation of treatment safety and long-term efficacy is essential. The present paper reports risk-benefit data at five years after glaucoma surgery from patients from the initial de Jong study. ${ }^{12}$

\section{Methods}

The study was conducted according to Dutch law and adhered to the tenets of the Helsinki Declaration. It was approved by the International Review Board at the Academic Medical Centre, Amsterdam University. All patients gave written informed consent before participating in the study.

The present analysis concerns data from the prospective randomized trial performed by de Jong. ${ }^{12}$ Patients were recruited at a single center (Amsterdam Academic Medical Center, Ophthalmology Department, The Netherlands). All glaucoma surgery was performed by one surgeon (LdJ) between October 2003 and November 2004.

Surgical details are described elsewhere. ${ }^{12}$ All surgeries were performed under topical anesthesia with Xylocaine ${ }^{\circledR}$ gel. Eyes randomized to EX-PRESS received the EX-PRESS $\mathrm{R} 50^{\circledR}$, a device developed for implantation under a scleral flap. The surgical procedures were similar in both treatment arms. During the whole procedure, only balanced salt solution was used to maintain or restore the anterior chamber, by injection through an additional corneal incision. No anterior chamber maintainer was used. A limbus-based conjunctival flap was dissected, followed by a " $4 \times 4 \mathrm{~mm} \times$ half the scleral thickness" scleral flap dissected up to the clear cornea. For the eyes randomized to EX-PRESS, a preincision was made into the anterior chamber using a $27 \mathrm{G}$ needle parallel to the iris, followed by EX-PRESS device implantation. In the eyes randomized to trabeculectomy, a sclerotomy was performed associated with a peripheral iridectomy. Sutures were identical for both procedures. The scleral flap was then sutured using 10-0 nylon sutures. The number of nylon sutures used to close the scleral flap depended on the judgment of the amount of filtration by the surgeon. The conjunctiva was sutured over the limbus with one uninterrupted, single-running Vicryl suture. Postoperatively, corticosteroids were given six times a day, and if pressures were below $5 \mathrm{mmHg}$ or the anterior chamber flattened, atropine $1 \%$ twice daily was added. The steroids were tapered over six weeks according to the extent of wound healing. During the first week, postoperative antibiotics four times a day were added.

All eligible patients were 18 years old or older, and all presented with primary open-angle glaucoma not controlled by maximally tolerated intraocular pressure medication. Patients with other ocular diseases or previous ocular surgery (apart from cataract extraction) were excluded. Eligible patients were assigned to receive either a unilateral EX-PRESS device inserted under a scleral flap or trabeculectomy, according to a computer-generated randomization list.

Optical assessments at baseline and at years 1, 2, 3, 4, and 5 after surgery included Goldmann tonometry ${ }^{16}$ to measure intraocular pressure and the Early Treatment Diabetic Retinopathy Study chart for visual acuity. ${ }^{17}$ In addition, a daytime intraocular pressure profile was performed six months after surgery at 9 am, $11 \mathrm{am}, 1 \mathrm{pm}$, and $4 \mathrm{pm}$.

Patients' responses were classified as: intraocular pressure values less than $15 \mathrm{mmHg}$ and $18 \mathrm{mmHg}$ thresholds; no subsequent intraocular pressure medication prescribed; and no further surgery performed for glaucoma control. Three response criteria were defined, ie, "marginal success" (outcome 1), "partial success" (outcomes 1 and 2), and "complete success" (outcomes 1, 2, and 3). Topical intraocular pressure medication was recorded at each visit. Overall intraocular pressure medication consumption and the average number of constituent medicinal entities (eg, DuoTrav ${ }^{\circledR}$ was 
counted twice, as travoprost and timolol) were determined at annual assessments. Unscheduled visits to other eye clinics and eye surgeries were also recorded.

\section{Statistical analysis}

According to the protocol, the primary response criterion was failure rate at one year, defined as intraocular pressure $\geq 18 \mathrm{mmHg}$ or the addition of an intraocular pressure-lowering medication. A sample of 40 patients per treatment group was needed to show a 32\% difference, ie, EX-PRESS $15 \%$ versus trabeculectomy $47 \%$, with alpha fixed at $5 \%$ and beta at $20 \%$ for a two-sided test.

All statistical analyses were performed using SAS 9.2 (SAS Institute, Cary, NC). Between-group comparisons were performed using two-sample $t$-tests for normally distributed continuous variables. When the latter criteria did not apply, the Wilcoxon's test, Fisher's Exact test, or Chi-square adjusted test was performed, depending on the sample size.

Daytime intraocular pressure profiles were analyzed by a repeated mixed analysis of variance that included three factors, ie, treatment, time, and patients. All factors were fixed, except for patients (random), in a full two-order model. A similar model was constructed for the intraocular pressure analysis comparing baseline with year 5 measurements. Complete, partial, and marginal success rates were evaluated using Kaplan-Meier survival curves and the log-rank test. Age adjustment employed linear models. The analysis was conducted on patients given an EX-PRESS device or standard trabeculectomy to one eye, and followed up for five years. All tests were interpreted at 5\%, twosided. No alpha adjustment was made for test multiplicity.

\section{Results}

Seventy-eight patients (39 per treatment group) participated in the analysis. Table 1 presents the baseline sociodemographic data. Both groups were comparable except for age, whereby patients receiving the EX-PRESS were younger than those undergoing trabeculectomy.

Baseline mean intraocular pressure values did not differ significantly either with or without age adjustment (Table 2). After EX-PRESS devices were implanted, patients showed stable intraocular pressure values $(P=0.67)$ spanning year 1 $(12.0 \mathrm{mmHg})$ to year $5(11.5 \mathrm{mmHg})$, whereas after trabeculectomy, intraocular pressure values decreased $(P<0.0001)$ from year $3(13.5 \mathrm{mmHg})$ to years $4(11.8 \mathrm{mmHg})$ and 5 $(11.3 \mathrm{mmHg})$. Up to the end of year 3 , intraocular pressure remained better controlled $(P=0.04)$ by EX-PRESS devices (intraocular pressure $12 \mathrm{mmHg}$ ) than by trabeculectomy (intraocular pressure $13.5 \mathrm{mmHg}$ ). During the remaining two years (to end of year 5) differences were not significant. Adjustment of patient age did not modify these conclusions.

Table 3 presents daytime intraocular pressure profiles six months after surgery. Patients in the trabeculectomy group had two times more intraocular pressure-lowering drug prescriptions. ${ }^{12}$ No time $\times$ treatment interaction was observed, indicating no corresponding time effect with either treatment. The differences between the EX-PRESS device and trabeculectomy did not reach statistical significance (no age adjustment, $P=0.075$; age-adjusted, $P=0.056$ ).

Table 4 shows intraocular pressure correlation coefficients for years 1-5 between intraocular pressure values at baseline and after cataract surgery. All correlation values were less than $r=0.4$ (recognized as clinically significant ${ }^{18,19}$ ) and none was statistically significant. Hence, intraocular pressure control after glaucoma surgery was independent of initial intraocular pressure values.

Tables 5 and 6 compare the success rates after EX-PRESS implantation and trabeculectomy with two different intraocular pressure thresholds (ie, $15 \mathrm{mmHg}$ and $18 \mathrm{mmHg}$ ). Success

Table I Patient characteristics and study follow-up

\begin{tabular}{|c|c|c|c|c|c|c|}
\hline & & \multicolumn{2}{|l|}{ EX-PRESS $^{\circledR}$} & \multicolumn{2}{|c|}{ Trabeculectomy } & \multirow[t]{2}{*}{$P$ value } \\
\hline & & $\mathbf{n}$ & $\%$ & $\mathbf{n}$ & $\%$ & \\
\hline \multirow[t]{2}{*}{ Gender } & Male & 19 & 48.7 & 27 & 69.2 & 0.07 \\
\hline & Female & 20 & 51.3 & 12 & 30.8 & \\
\hline \multirow[t]{3}{*}{ Race } & Caucasian & 3 & 84.6 & 36 & 92.3 & 0.40 \\
\hline & Black & 4 & 10.3 & 3 & 7.7 & \\
\hline & Asian & 2 & 5.1 & 0 & 0 & \\
\hline \multirow[t]{3}{*}{ Glaucoma type } & POAG & 37 & 94.9 & 39 & 100 & 0.49 \\
\hline & PXFG & 1 & 2.55 & 0 & 0 & \\
\hline & Pigmentary & I & 2.55 & 0 & 0 & \\
\hline \multirow[t]{2}{*}{ Age } & Mean (SD) & $62.4(14.7)$ & & $68.6(11.5)$ & & 0.04 \\
\hline & Range & $26-86$ & & $37-83$ & & \\
\hline \multirow[t]{2}{*}{ Total follow-up (weeks) } & Mean (SD) & $262.4(4.0)$ & & $265.6(13.8)$ & & 0.16 \\
\hline & Range & $251.3-272.2$ & & $251.3-313.9$ & & \\
\hline
\end{tabular}

Abbreviations: SD, standard deviation; POAG, primary open-angle glaucoma; PXFG, pseudoexfoliation glaucoma. 
Table 2 Mean ( \pm standard deviation) intraocular pressure values

\begin{tabular}{|c|c|c|c|c|c|c|}
\hline \multirow[t]{2}{*}{ IOP (mmHg) } & \multicolumn{3}{|c|}{ Without age adjustment } & \multicolumn{3}{|c|}{ Adjusted on age } \\
\hline & EX-PRESS & Trabeculectomy & $P$ value & EX-PRESS & Trabeculectomy & $P$ value \\
\hline Before surgery & $22.8(8.0)$ & $21.3(5.6)$ & 0.34 & $23.6(7.0)$ & $20.7(7.0)$ & 0.09 \\
\hline Year I & $12.0(2.7)$ & $13.9(4.3)$ & 0.02 & $12.2(3.8)$ & $13.9(3.8)$ & 0.05 \\
\hline Year 2 & $11.9(2.9)$ & I3.8 (3.2) & 0.01 & $12.0(3.3)$ & I3.8 (3.2) & 0.01 \\
\hline Year 3 & $12.0(3.1)$ & $13.5(3.3)$ & 0.04 & I2.I (3.4) & $13.5(3.4)$ & 0.08 \\
\hline Year 4 & II.3 (2.5) & II $.8(2.4)$ & 0.35 & II.4 (2.5) & II.6 (2.5) & 0.69 \\
\hline Year 5 & II .5 (2.9) & II.3 (I.9) & 0.73 & $\mathrm{II} .4(2.2)$ & II.2 (2.2) & 0.71 \\
\hline
\end{tabular}

Abbreviation: IOP, intraocular pressure.

rates during years 1-3 after EX-PRESS were significantly higher for both thresholds, compared with trabeculectomy, without inclusion of medications. When medication efficacy was considered, differences did not reach statistical significance, although EX-PRESS implantations continued to show higher success rates up to year 3 .

Time to treatment failure according to the three different response criteria is depicted in Figure 1. With the $15 \mathrm{mmHg}$ intraocular pressure threshold, EX-PRESS implantation produced significantly higher success rates than trabeculectomy with all three criteria (Figures 1D, 1E, and 1F). When $18 \mathrm{mmHg}$ was the intraocular pressure threshold, the success rate of EX-PRESS implantation was again higher with all criteria, and significantly so for two criteria (Figures 1A and $1 \mathrm{~B})$.

The use of topical intraocular pressure medication is shown in Table 7. At all follow-up assessments, the likelihood of being prescribed an intraocular pressure medication was less after EX-PRESS implantation than after trabeculectomy.

Lastly, complications during the follow-up period indicated that more surgical interventions followed trabeculectomy than after EX-PRESS implantation. Trabeculectomy patients experienced more needling ( 9 versus 3 ) and cataract surgery than EX-PRESS patients (8 versus 5 ).

\section{Discussion}

The present report is the first long-term efficacy comparison of trabeculectomy and the EX-PRESS glaucoma filtration device based on a randomized clinical trial. Patients implanted with EX-PRESS were more frequent responders, had better intraocular pressure control during the first three years, and fewer intraocular pressure drug prescriptions, compared with standard trabeculectomy. Thus, the results reported at one year by de Jong et $\mathrm{al}^{12}$ persisted beyond the initial follow-up period. The technical aspects of EX-PRESS implantation and its short-term complications were discussed extensively in the former paper. This extension report confirms those points, except that subsequent surgical interventions for glaucoma were more frequent in the trabeculectomy group than in the EX-PRESS group. However, the difference was not statistically significant because such events were rare and sample sizes were small.

The study was performed at a single center and all operations were by the same surgeon. Accordingly, the variance of our efficacy estimates may have been reduced by practice effects, thus increasing the sensitivity of the study to differences between EX-PRESS implantation and standard trabeculectomy. This would limit the extrapolation of our results to other centers and countries.

However, the study can be compared with others on the basis of its trabeculectomy control group. First, the intraocular pressure drug prescription rates after trabeculectomy were close to those of Papaconstantinou et $a,{ }^{20}$ who reported a prescription rate of 0.5 items at six months, which is similar to the present rate of 0.74 items at one year. Second, Gedde et $\mathrm{al}^{21}$ reported a mean intraocular pressure of $13.3 \pm 6.8 \mathrm{mmHg}$ three years after trabeculectomy, which compares with the present $13.5 \pm 3.3 \mathrm{mmHg}$ with a similar number of prescribed drugs. Third, according to Geffen et al, ${ }^{22}$ intraocular pressure values ranged from 6 to $21 \mathrm{mmHg}$ (mean decrease 20\%) four years after subconjunctival

Table 3 Daytime intraocular pressure profiles at six months after surgery

\begin{tabular}{|c|c|c|c|c|}
\hline \multirow{2}{*}{$\begin{array}{l}\text { IOP after surgery } \\
\text { at } 6 \text { months }\end{array}$} & \multicolumn{2}{|c|}{ Without age adjustment } & \multicolumn{2}{|c|}{ Age-adjusted } \\
\hline & EX-PRESS & Trabeculectomy & EX-PRESS & Trabeculectomy \\
\hline $9 \mathrm{am}$ & 10.6 & 11.5 & 11.8 & 12.6 \\
\hline II am & 10.7 & 11.8 & 12.0 & 12.9 \\
\hline I pm & II.I & 11.6 & 12.2 & 12.8 \\
\hline $4 \mathrm{pm}$ & II.I & 11.7 & 12.1 & 13.0 \\
\hline
\end{tabular}

Abbreviation: IOP, intraocular pressure. 
Table 4 Correlations between baseline and postoperative intraocular pressure measurements

\begin{tabular}{|c|c|c|c|}
\hline $\begin{array}{l}\text { Correlation with } \\
\text { baseline IOP }\end{array}$ & EX-PRESS & Trabeculectomy & All patients \\
\hline Year I $r=$ & -0.123 & -0.052 & -0.111 \\
\hline$P=$ & 0.46 & 0.75 & 0.34 \\
\hline Year $2 r=$ & -0.14 & 0.25 & 0.023 \\
\hline$P=$ & 0.41 & 0.12 & 0.85 \\
\hline Year $3 r=$ & 0.029 & 0.150 & 0.044 \\
\hline$P=$ & 0.87 & 0.36 & 0.70 \\
\hline Year $4 r=$ & 0.087 & 0.191 & 0.110 \\
\hline$P=$ & 0.60 & 0.24 & 0.34 \\
\hline Year $5 r=$ & 0.214 & -0.048 & 0.140 \\
\hline$P=$ & 0.20 & 0.77 & 0.23 \\
\hline
\end{tabular}

Abbreviation: IOP, intraocular pressure.

topical lidocaine anesthesia and trabeculectomy without further glaucoma therapy or repeat filtration surgery, comparable with the present $46.2 \%$ after four years (although the success criteria differed slightly). Fourth, Gilmour et $\mathrm{al}^{23}$ reported a $42 \%$ successful outcome (intraocular pressure $<18 \mathrm{mmHg}$, without intraocular pressure medication) at 40 months, similar to the present $41.0 \%$ success rate at three years. Lastly, Yalvac et $\mathrm{al}^{24}$ observed complete success (intraocular pressure 6-21 mmHg, without medication) in $66.2 \%$ of eyes at six months after trabeculectomy and $55.1 \%$ at three years. Our corresponding findings were $61.5 \%$ at one year and $41.0 \%$ at three years, the latter discrepancy probably being explained by our $18 \mathrm{mmHg}$ intraocular pressure threshold. The aforegoing results need to be confirmed by a multicenter, randomized, clinical trial for broader population inferences.

The present intraocular pressure effect of EX-PRESS implantation was approximately $1.5 \mathrm{mmHg}$ greater than for trabeculectomy over three years, which is clinically relevant at a population level. Also, the standard deviation of intraocular pressure was reduced after glaucoma surgery, indicating that EX-PRESS implantations provided good intraocular pressure control for most patients (ie, no outliers) and that the procedure effectiveness is predictable. Furthermore, postoperative intraocular pressure values were independent of their baseline values, suggesting that even the most severe cases could benefit from such treatment and achieve intraocular pressure values of $11.5 \mathrm{mmHg}$ at five years. Hence, intraocular pressure control using EX-PRESS is clinically relevant and predictable, and may be offered to even the most severe patients. Visual field measurements and quality of life effects should be investigated by future long-term trials.

The intraocular pressure benefits of EX-PRESS implantation, compared with standard trabeculectomy, persisted for three years and remained stable over five years. By contrast, standard trabeculectomy produced a lesser intraocular pressure reduction during the first three years, matching the EX-PRESS intraocular pressure effect only at four and five years, on average. The difference may be explained by trabeculectomy patients receiving more intraocular pressure medication, with prescription adjustments, before they matched the intraocular pressure effect. Moreover, trabeculectomy patients required more needling during follow-up visits. The overall implication is that patients given EX-PRESS implantation may call upon fewer medical resources, which may generate savings compared with standard trabeculectomy. A full health economics evaluation is needed for precise estimates.

Several limitations apply to this analysis. First, the physician knew which treatment was given when measuring intraocular pressure and writing intraocular pressure drug prescriptions, although intraocular pressure is a rather objective measure. Second, the study was limited to one center and surgeon, raising possible questions about practice effects, as discussed, and extrapolation to other populations. Third, patients were operated on one eye only, which introduces the possibility that intraocular pressure drugs instilled into the nonoperated eye might interact with the operated eye. Fourth, it may be questioned whether resources expended on intraocular pressure medication were truly stochastic variables, or driven by the protocol. Resources dedicated to control intraocular pressure after surgery might be different from those reported in this trial. Fifth, with the sample size fixed ad hoc, the observed number of patients does not allow reliable inferences concerning the incidence rates of long-term adverse events (eg, needling). Additional studies,

Table 5 Intraocular pressure success rates $(\leq 18 \mathrm{mmHg})$

\begin{tabular}{|c|c|c|c|c|c|c|}
\hline \multirow{2}{*}{$\begin{array}{l}\text { IOP } \leq 18 \\
\mathrm{mmHg}\end{array}$} & \multicolumn{3}{|c|}{ Without IOP medication } & \multicolumn{3}{|c|}{ Including IOP medication } \\
\hline & EX-PRESS & Trabeculectomy & $P$ value & EX-PRESS & Trabeculectomy & $P$ value \\
\hline Year I & $86.8 \%$ & $61.5 \%$ & 0.01 & $100 \%$ & $89.7 \%$ & 0.06 \\
\hline Year 2 & $76.3 \%$ & $51.3 \%$ & 0.02 & $97.3 \%$ & $92.3 \%$ & 0.62 \\
\hline Year 3 & $66.7 \%$ & $41.0 \%$ & 0.02 & $97.4 \%$ & $92.3 \%$ & 0.62 \\
\hline Year 4 & $64.1 \%$ & $46.2 \%$ & 0.11 & $100 \%$ & $100 \%$ & 1.00 \\
\hline Year 5 & $59.0 \%$ & $46.2 \%$ & 0.25 & $97.4 \%$ & $100 \%$ & 0.49 \\
\hline
\end{tabular}

Abbreviation: IOP, intraocular pressure. 
Table 6 Intraocular pressure success rates $(\leq 15 \mathrm{mmHg})$

\begin{tabular}{|c|c|c|c|c|c|c|}
\hline \multirow{2}{*}{$\begin{array}{l}\mathrm{IOP} \leq 15 \\
\mathrm{mmHg}\end{array}$} & \multicolumn{3}{|c|}{ Without IOP medication } & \multicolumn{3}{|c|}{ Including IOP medication } \\
\hline & EX-PRESS & Trabeculectomy & $P$ value & EX-PRESS & Trabeculectomy & $P$ value \\
\hline Year I & $80.0 \%$ & $51.3 \%$ & 0.01 & $86.8 \%$ & $76.9 \%$ & 0.26 \\
\hline Year 2 & $71.1 \%$ & $48.7 \%$ & 0.046 & $89.2 \%$ & $64.1 \%$ & 0.01 \\
\hline Year 3 & $66.7 \%$ & $38.5 \%$ & 0.01 & $87.2 \%$ & $79.5 \%$ & 0.36 \\
\hline Year 4 & $61.5 \%$ & $46.2 \%$ & 0.17 & $94.9 \%$ & $89.7 \%$ & 0.24 \\
\hline Year 5 & $59.0 \%$ & $46.2 \%$ & 0.26 & $92.1 \%$ & $94.9 \%$ & 0.32 \\
\hline
\end{tabular}

Abbreviation: IOP, intraocular pressure.
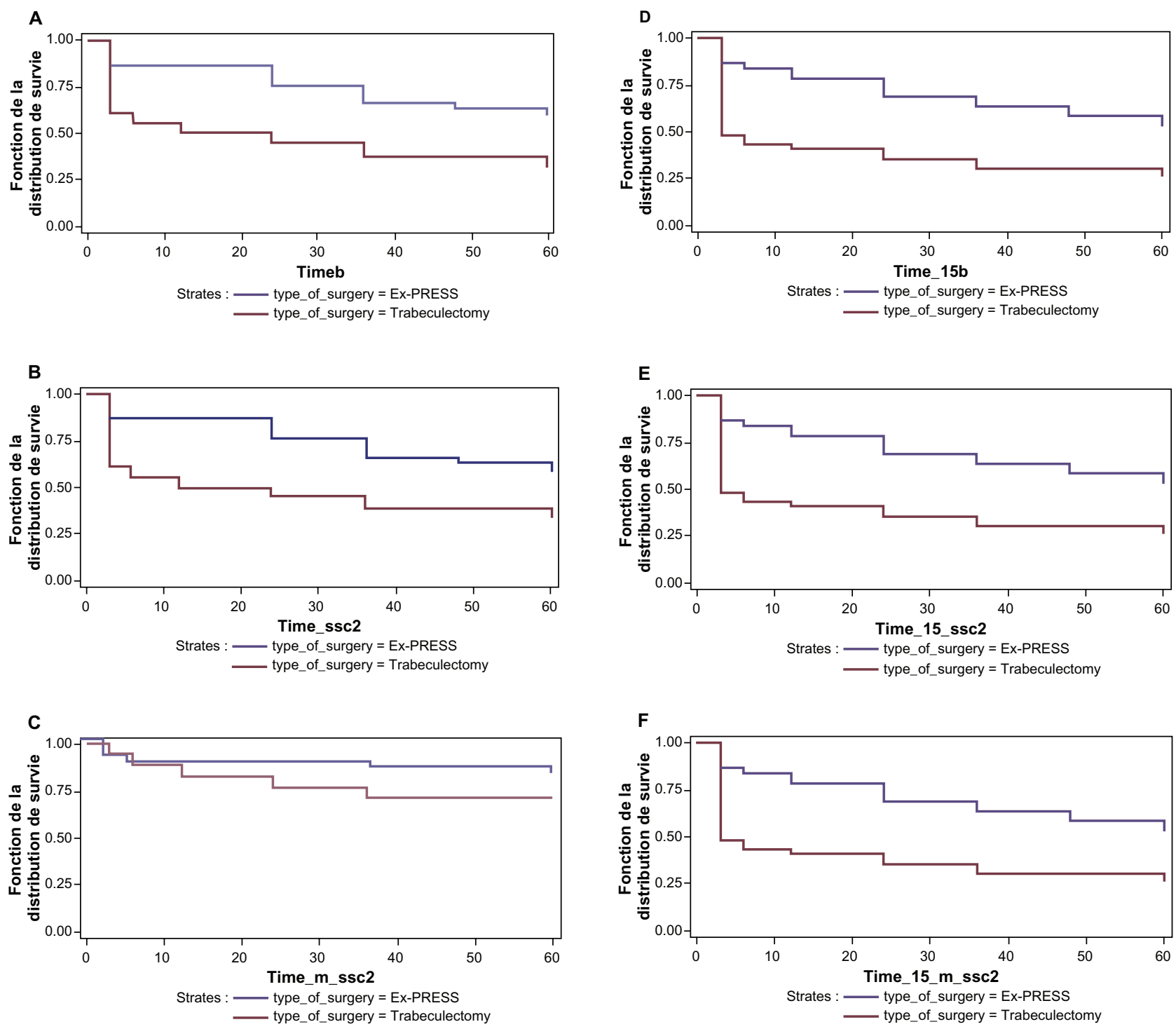

Figure I Survival curves comparing Ex-PRESS implants with trabeculectomy. A) Kaplan-Meier life table curves of complete success (IOP $\leq$ I8 mmHg): no IOP medication or subsequent glaucoma surgery (log-rank, $p=0.0049$ ). B) Kaplan-Meier life table curves of partial success (IOP $\leq 18 \mathrm{mmHg}$ ), i.e. including IOP medication: no subsequent glaucoma surgery (log-rank, $p=0.0085)$. C) Kaplan-Meier life table curves for marginal success (IOP $\leq 18 \mathrm{mmHg}$ ) incorporating IOP medication and subsequent glaucoma surgery (log-rank, $p=0.18$ ). D) Kaplan-Meier life table curves of complete success (IOP $\leq 15 \mathrm{mmHg}$ ): no IOP medication or subsequent glaucoma surgery (log-rank, $p=0.0014)$. E) Kaplan-Meier life table curves of partial success (IOP $\leq 15 \mathrm{mmHg}$ ) i.e. including IOP medication: no subsequent glaucoma surgery (log-rank, $p=0.0026)$. F) Kaplan-Meier life table curves of partial success (IOP $\leq 15 \mathrm{mmHg}$ ) i.e. including IOP medication: no subsequent glaucoma surgery (log-rank, $p=0.0026)$.

recruiting larger samples and conducted at more centers, are needed to confirm the five-year results.

In conclusion, this five-year analysis confirmed the results presented at one year by de Jong et al. ${ }^{12}$ EX-PRESS implantations are more effective than standard trabeculectomy in controlling intraocular pressure during the first three years. This result was obtained with fewer subsequent surgical interventions and less topical intraocular pressure medication. 
Table 7 Intraocular pressure drug prescriptions

\begin{tabular}{|c|c|c|c|c|c|c|}
\hline & \multicolumn{3}{|l|}{ EX-PRESS } & \multicolumn{3}{|c|}{ Trabeculectomy } \\
\hline & $\begin{array}{l}(\mathrm{n}) \% \text { treated } \\
\text { patients }\end{array}$ & $\begin{array}{l}\text { Mean number of drugs } \\
\text { (treated patients) }\end{array}$ & $\begin{array}{l}\text { Mean number of } \\
\text { drugs (all patients) }\end{array}$ & $\begin{array}{l}(\mathrm{n}) \% \text { treated } \\
\text { patients }\end{array}$ & $\begin{array}{l}\text { Mean number of drugs } \\
\text { (treated patients) }\end{array}$ & $\begin{array}{l}\text { Mean number of } \\
\text { drugs (all patients) }\end{array}$ \\
\hline Year I & (5) $12.8 \%$ & 2.4 & 0.31 & (I4) $35.9 \%$ & 2.1 & 0.74 \\
\hline Year 2 & (9) $23.1 \%$ & 2.1 & 0.49 & (I7) $43.6 \%$ & 2.4 & 1.05 \\
\hline Year 3 & (I3) $33.3 \%$ & 1.8 & 0.62 & (2I $53.9 \%$ & 2.4 & 1.28 \\
\hline Year 4 & (I4) $35.9 \%$ & 1.9 & 0.69 & (2I) $53.9 \%$ & 2.5 & 1.33 \\
\hline Year 5 & (I6) $41.0 \%$ & 2.1 & 0.85 & (2I) $53.9 \%$ & 2.0 & 1.10 \\
\hline
\end{tabular}

\section{Disclosure}

This study was supported by a grant from Alcon Management SA, Geneva, Switzerland.

\section{References}

1. Henson DB, Thampy R. Preventing blindness from glaucoma. $B M J$. 2005;331(7509):120-121.

2. Kingman S. Glaucoma is second leading cause of blindness globally. Bull World Health Organ. 2004;82(11):887-888.

3. Quigley HA, Broman AT. The number of people with glaucoma worldwide in 2010 and 2020. Br J Ophthalmol. 2006;90(3):262-267.

4. Caprioli J, Coleman AL. Intraocular pressure fluctuation a risk factor for visual field progression at low intraocular pressures in the Advanced Glaucoma Intervention Study. Ophthalmology. 2008;115(7):1123-1129.

5. Keltner JL, Miller JP, Parrish RK 2nd, Wilson MR, Kass MA. The Ocular Hypertension Treatment Study: Baseline factors that predict the onset of primary open-angle glaucoma. Arch Ophthalmol. 2002;120(6):714-720.

6. European Glaucoma Society. Terminology and Guidelines for Glaucoma. 3rd ed. Available at: http://www.eugs.org/eng/EGS_guidelines. asp. Accessed January 21, 2011.

7. Mantravadi AV, Myers JS. Reconsidering trabeculectomy's strengths and weaknesses. Clin Experiment Ophthalmol. 2010;38(9):827-828.

8. Maris PJ Jr, Ishida K, Netland PA. Comparison of trabeculectomy with EX-PRESS miniature glaucoma device implanted under scleral flap. J Glaucoma. 2007;16(1):14-19.

9. Wamsley S, Moster MR, Rai S, Alvim HS, Fontanarosa J. Results of the use of the EX-PRESS miniature glaucoma implant in technically challenging, advanced glaucoma cases: A clinical pilot study. Am J Ophthalmol. 2004;138(6):1049-1051.

10. Dahan E, Carmichael TR. Implantation of a miniature glaucoma device under a scleral flap. J Glaucoma. 2005;14(2):98-102.

11. Traverso CE, De Feo F, Messas-Kaplan A, et al. Long term effect on IOP of a stainless steel glaucoma drainage implant (EX-PRESS) in combined surgery with phacoemulsification. Br J Ophthalmol. 2005;89(4):425-429.

12. De Jong L. The EX-PRESS glaucoma shunt versus trabeculectomy in open-angle glaucoma: A prospective randomized study. Adv Ther. 2009;26(3):336-345.
13. Maris PJG, Ishida K, Netland P. Comparison of trabeculectomy with EX-PRESS miniature glaucoma device implanted under scleral flap. J Glaucoma. 2007;16(1):14-19.

14. Gandolfi S, Traverso CF, Bron A, Sellem E, Kaplan-Messas A, Belkin M. Short-term results of a miniature draining implant for glaucoma in combined surgery with phacoemulsification. Acta Ophthalmol Scand Suppl. 2002;236:66.

15. Kaplan-Messas A, Traverso CF, Sellem E, Zbigniew Z, Belkin M. The EX-PRESS miniature glaucoma implant in combined surgery with cataract extraction: Prospective study. Invest Ophthalmol Vis Sci. 2002;43:3348A.

16. Moses RA. The Goldmann applanation tonometer. Am J Ophthalmol. 1958;46(6):865-869.

17. Camparini M, Cassinari P, Ferrigno L, Macaluso C. ETDRS-fast: Implementing psychophysical adaptive methods to standardized visual acuity measurement with ETDRS charts. Invest Ophthalmol Vis Sci. 2001;42(6):1226-1231.

18. Campbell DT, Fiske DW. Convergent and discriminant validation by the multitrait-multimethod matrix. Psychol Bull. 1959;56(2):81-105.

19. Hays R, Hayashi T. Beyond internal consistency reliability: Rationale and user's guide for multitrait analysis program on the microcomputer. Behav Res Methods Instrum Comput. 1990;22:167-175.

20. Papaconstantinou D, Georgalas I, Karmiris E, et al. Trabeculectomy with OloGen versus trabeculectomy for the treatment of glaucoma: A pilot study. Acta Ophthalmol. 2010;88(1):80-85.

21. Gedde SJ, Schiffman JC, Feuer WJ, Herndon LW, Brandt JD, Budenz DL; Tube Versus Trabeculectomy Study Group. Three-year follow-up of the tube versus trabeculectomy study. Am J Ophthalmol. 2009; 148(5):670-684.

22. Geffen N, Carrillo MM, Jin Y, Trope GE, Buys YM. Effect of local anesthesia on trabeculectomy success. J Glaucoma. 2008;17(8):658-661.

23. Gilmour DF, Manners TD, Devonport H, Varga Z, Solebo AL, Miles J. Viscocanalostomy versus trabeculectomy for primary open angle glaucoma: 4-year prospective randomized clinical trial. Eye. 2009;23(9):1802-1807.

24. Yalvac IS, Sahin M, Eksioglu U, Midillioglu IK, Aslan BS, Duman S. Primary viscocanalostomy versus trabeculectomy for primary openangle glaucoma: Three-year prospective randomized clinical trial. J Cataract Refract Surg. 2004;30(10):2050-2057.
Clinical Ophthalmology

\section{Publish your work in this journal}

Clinical Ophthalmology is an international, peer-reviewed journal covering all subspecialties within ophthalmology. Key topics include: Optometry; Visual science; Pharmacology and drug therapy in eye diseases; Basic Sciences; Primary and Secondary eye care; Patient Safety and Quality of Care Improvements. This journal is indexed on Submit your manuscript here: http://www.dovepress.com/clinical-ophthalmology-journal

\section{Dovepress}

PubMed Central and CAS, and is the official journal of The Society of Clinical Ophthalmology (SCO). The manuscript management system is completely online and includes a very quick and fair peer-review system, which is all easy to use. Visit http://www.dovepress.com/ testimonials.php to read real quotes from published authors. 